\title{
DA INDIVISIBILIDADE DOS DIREITOS HUMANOS E A PROTEÇÃO DO TRABALHO DIGNO EM UM MUNDO GLOBALIZADO
}

\section{INDIVISIBILITY OF HUMAN RIGHTS AND PROTECTION OF DECENT WORK IN A GLOBALIZED WORLD}

Lourival José de Oliveira Lourival.oliveira40@hotmail.com

Recebido em: 17/03/2014

Aprovado em:08/09/2014

Sumário: 1.Introdução. 2.Características dos direitos surgidos das relações do trabalho. 3.O Estado Nacional nas relações de trabalho diante da possibilidade da criação de espaços públicos transnacionais. 4. A nova forma de produzir e a solução dos conflitos nas relações de trabalho transnacionalizada. 5. Da necessidade da construção de um padrão internacional de proteção ao trabalho humano. 6. Conclusão. Referências bibliográficas

\section{Resumo:}

A premissa inicial circunscreve-se à constatação de que os procedimentos de produção se internacionalizaram. Consequentemente, a partir da produção compartilhada ou em espaços definidos, obteve-se, como um dos resultados principais, a precarização do trabalho humano, considerando-se que, no plano nacional, diante das políticas liberalizantes, não vem se tornando mais possível ao Estado nacional assegurar as garantias mínimas de proteção ao trabalho. Para enfrentar essa realidade, o presente artigo propõe a construção de novos espaços públicos, com a participação de vários atores internacionais, não mais se restringindo aos entes públicos internacionais existentes, sendo que a proteção ao trabalho humano deverá ser promovida, na condição de direito fundamental, levando-se em conta o contexto global e a

\section{Abstract:}

The initial premise is limited to the finding that the production procedures internationalized . Consequently, from the production sharing or defined spaces, was obtained as one of the main results the precariousness of human labor, considering that at the national level, given the liberalizing policies, is not making it possible to ensure the national state minimum safeguards to protect the work. To address this reality, this paper proposes the construction of new public spaces, with the participation of several international actors, no longer confining to existing international public entities, and the protection of human work should be promoted, provided fundamental right, taking into account the global context and the thematic multidisciplinary. It is the job of the holistic view, which assumes the interdependence, 
multidisciplinariedade temática. Trata-se do emprego da visão holística, que pressupõe a interdependência, a indivisibilidade dos direitos humanos, como pressuposto essencial a fim de equilibrar o desenvolvimento econômico com o desenvolvimento social no plano internacional.

\section{Palavras-chave:}

Direitos Fundamentais; globalização; indivisibilidade dos Direitos Humanos; trabalho digno. indivisibility of human rights as a prerequisite in order to balance economicdevelopment with social development internationally.

\section{Keywords:}

Fundamental rights, globalization, indivisibility of human rights, decent work.

\section{Introdução}

É sabido que as relações econômicas e comerciais expandiram-se no mundo, a ponto de se configurar um compartilhamento de várias empresas, situadas em territórios diferentes, na produção de mesmo produto ou de mesma prestação de serviço. Essas empresas distintas, em lugares diversos, participam de estágios da produção, todavia ao final, com o produto acabado ou o serviço prestado, não é fácil identificar a forma, o procedimento e muito menos o número de empresas que se associaram ao processo de produção.

Esse procedimento faz com que trabalhadores de várias nacionalidades juntem-se na produção de um mesmo bem ou na prestação de certo serviço, ainda que localizados geograficamente em Estados diferentes, na maioria das vezes também de nacionalidades diferentes. Desse processo temse uma série de resultados, dentre eles, a dificuldade de o trabalhador em identificar para quem estava produzindo, ou até mesmo o que ele estava produzindo, o que contribui, em grande parte, para aquilo que se convencionou chamar de individualismo na produção.

Pode-se aqui trazerem à baila outras situações que se juntam a essa e que não serão alvo neste artigo, como, por exemplo, as transferências constantes de trabalhadores ligados à mesma empresa de uma localidade para outra, ou às migrações maciças de trabalhadores, que ocorrem por conta de vários fatores, podendo ser citados: a estagnação da possibilidade de sobrevivência do trabalhador em sua localidade de origem ou da formação dos chamados blocos econômicos, que levam à facilitação da movimentação de trabalhadores dentro do mesmo bloco ou ainda das mudanças repentinas da empresa de uma localidade para outra, ou de mudanças de investimentos na produção, tornando-se essa última em polo de atração para grande massa de trabalhadores, muitas vezes, nesse caso, produzindo postos de trabalho sem qualquer qualidade. 
Enfim, a prestação de trabalho no mundo e transnacionalizou-se a partir da segunda metade do século XX, principalmente. Esse fenômeno ocorreu na mesma proporção e velocidade da transnacionalização do capital, não sendo possível tratar os dois fenômenos separadamente. Ocorre que ao contrário dos estudos e da evolução dos mecanismos de aperfeiçoamento técnico para lidar com essa nova configuração, o mesmo não ocorreu em relação ao trato com as relações de trabalho no que se refere à proteção ao trabalho humano e à construção de procedimentos que fossem compatíveis, na mesma proporção, com os instrumentos construídos pelo capital.

João Bosco M. Machado (2009, pp. 3 e 4), tratando sobre integração produtiva e os seus reflexos afirma:

A integração produtiva deve ser entendida como o desenvolvimento do processo de fragmentação da produção em bases regionais (grupos de países) ou globais, o que pode implicar a criação de uma divisão internacional do trabalho no circuito de uma determinada cadeia produtiva, cuja contrapartida é a consolidação de fluxos comerciais do tipo intra-industrial em que ocorrem importação de partes e componentes, processamento industrial e exportação de componentes mais complexos ou de produtos finais. Há, portanto, circunstâncias em que o processo de outsourcing conduz unicamente à formação de redes locais de fornecedores o que caracterizaria, no contexto da abordagem aqui sugerida, terceirização da produção, sem integração produtiva5. É óbvio que a integração produtiva dá lugar a transações comerciais, mas não apenas a isso. Implica, como dito, o estabelecimento entre parceiros de um "compromisso de partilha" de ativos específicos, numa operação que transcende à simples compra e venda de bens e serviços (Coriat et alli, 1994). Por conseguinte, o conceito de integração produtiva aqui sugerido é mais abrangente do que a noção de fragmentação da produção, na medida em que o primeiro engloba a conformação de alianças ou cooperação entre empresas, o que implica a criação de uma divisão internacional do trabalho no âmbito de uma cadeia produtiva. Este movimento é liderado por grandes empresas em parceira com pequenas e médias empresas (PMEs), gera fluxos de comércio e de investimento entre países e, em geral, é estimulado pela liberalização comercial ou por acordos de integração. (MACHADO, 2014, pp. 3 e 4) 
Logicamente que nada ocorre por acaso. O não desenvolvimento das organizações sindicais no plano internacional, ou a não evolução no plano internacional da proteção ao trabalho humano (não querendo aqui desconsiderar os avanços obtidos pela OIT nas últimas décadas), a não aderência dos Estados a um plano que estabelecesse de fato proteções mínimas para os trabalhadores e o próprio descaso de organizações internacionais, como, exemplo, a Organização das Nações Unidas, demonstram a crescente privatização que vem ocorrendo dos espaços internacionais.

Vários resultados danosos foram produzidos em virtude desse contexto globalizado, valendo citar o surgimento de novas formas de doenças profissionais ou do trabalho, continuidade em alguns setores da elevação do número de acidentes de trabalho, o uso da mão de obra infantil na produção em várias regiões do planeta, tratamento diferenciado nas relações de trabalho, de acordo com o sexo, nacionalidade, etnias, religiões e outras tantas consequências que afrontam os próprios direitos humanos são exemplos gritantes que comprovam que intencionalmente a proteção ao trabalho humano, dentro do contexto globalizado, não foi visto como importante, ou não foi tratado com a valoração que é devida a um direito fundamental.

De forma oposta, a não evolução da proteção ao trabalho humano no plano supranacional, globalizado, foi algo previamente estabelecido para não acontecer, por conta que foi justamente em razão dessa não proteção que se tornou possível criar um sistema que se propôs, por meio da migração contínua do capital, com investimentos no deslocamento de empresas de uma região para outra, a obter o crescimento na lucratividade, baseado especialmente na redução do custo da mão d -obra, o que contribuiu para o crescente processo de precarização do trabalho humano.

O presente artigo fará um recorte e tentará estabelecer um estudo sobre a necessidade da construção de espaços públicos internacionais, para o fim de efetivar a proteção dos direitos decorrentes das relações do trabalho. Apresentará novas formas de prevenção e ou solução de conflitos nas relações de trabalho, assim como identificará pontos de contato entre a proteção do trabalho humano e outros valores que também se caracterizam como Direitos Fundamentais, de forma a construir um esforço sinérgico em torno da obtenção do resultado da dignidade da pessoa humana. 
Por último, deseja contribuir para a construção de um sistema que possa proteger, ainda que diante de um conflito, o valor do trabalho humano, partindo-se da interação e da integração dos sistemas nacional e internacional, compondo um conjunto normativo e de ações coletivas e efetivas, a partir da geração de espaços públicos transnacionais e da participação de novos atores internacionais no processo de garantidor dos direitos laborais.

Para tanto, foi adotado aqui o método dedutivo, classificando os direitos surgidos das relações de trabalho como direitos fundamentais, cuja proteção importa na própria proteção dos Direitos Humanos.

\section{Características dos direitos surgidos das relações do trabalho}

1. Segundo publicação da OIT (Organização Internacional do Trabalho) datada de janeiro/2014, com o título "Mundo perde 62 milhões de empregos", destaca-se os resultados produzidos pela crise financeira de 2008, que segundo a entidade, expulsou mais de 202 milhões de pessoas dos seus empregos. Também na mesma nota revela-se a grande concentração de renda que equivale a dizer que 1\% da população mundial tem metade da riqueza global. Para a OIT, a recuperação da economia não está sendo seguida por uma geração de postos de trabatho e a previsão é de que, em 2018, 215 milhões de pessoas não terão emprego no mundo. Os esforços para a redução da pobreza foi afetada pela crise, ao ponto da disparidade social no planeta aumentou consideravelmente a partir de 2008. 0 grupo de $1 \%$ mais rico tem renda 65 vezes superior aos 50\% mais pobres. Disponivel em: http://economia.estadao. com.br/noticias/economia-internacional,mundo-perde-62-milhoes-de-empregos, 175819,0.htm, Acesso em: 10 fev. 2014.
A dura questão a ser enfrentada pelo Direito do Trabalho, que se constitui também na principal razão da sua existência, é o enfrentamento do desequilíbrio entre o valor social do trabalho humano e o poder econômico, que pode ser traduzido na seguinte equação: crescente desenvolvimento do poder econômico sem o correspondente e necessário desenvolvimento social. ${ }^{1}$

No plano da Constituição Federal, é preciso fazer com que a ordem econômica esteja realmente fundada na valorização do trabalho humano, considerando aqui o trabalho nas suas mais diversas formas de prestação e não apenas o trabalho realizado por meio de contrato de emprego, que nada mais é que a colocação em prática da determinação contida no artigo 170 da Constituição Federal.

Nos ensinamentos de Américo Plá Rodrigues, o Direito do Trabalho está fundado em seis princípios, que objetivam produzir a redução da desigualdade entre empregado e empregador, sendo eles: princípio da proteção, da irrenunciabilidade, da continuidade, da primazia da realidade, da continuidade, da razoabilidade e da boa-fé (RODRIGUES, 1978).

Dando sequência ao estudo sobre o mesmo ponto, Godinho Delgado também registra que o Direito do Trabalho é formado pelo conjunto de nove princípios, citando-os: princípio da proteção, da norma mais favorável, da imperatividade da norma trabalhista, da indisponibilidade dos direitos trabalhistas, da condição mais benéfica, da inalterabilidade contratual lesiva, da intangibilidade salarial, da primazia da 
realidade e da continuidade da relação de emprego (DELGADO, 2013, p. 189). A questão principal é como fazer valer esses princípios diante da nova dinâmica hoje existente no tocante à forma de se produzir, levandose em conta noções de tempo, espaço, técnicas de produção, circulação de mercadorias, redução da intervenção dos Estados nacionais no sistema produtivo, concentração do poder econômico, capital especulativo e outros tantos.

A impressão que se tem, somente a título de provocação, é que a maioria desses princípios foi sistematizada levando-se em conta apenas o plano nacional, partindo-se de um Estado nacional detentor de poder interventivo e garantidor da segurança mínima para o trabalhador. Ou seja, sem considerar a nova dinâmica construída pelo capital globalizado, que promoveu a reforma quase por completa na forma de produzir ou de realizar o trabalho. ${ }^{2}$

No entanto, não existe outra maneira de começar o estudo que aqui se pretende, a não ser partir da conceituação e da caracterização dos chamados direitos proveniente do trabalho humano, levando-se em conta o contexto internacional.

O primeiro aspecto a ser estudado é saber se os direitos chamados de direitos trabalhistas ou do trabalho são ou não são direitos fundamentais e por consequência pertencentes ao rol dos Direitos Humanos.

A elucidação desse ponto é de grande e vital importância, considerando que toda a construção se dará sobre aquilo que for estabelecido a partir dessa premissa. Alguns estudiosos do assunto, valendo citar Fábio Siebeneichler de Andrade e Andressa da Cunha Gudde (2013, p. 15), no mesmo artigo, afirmam que:

Estabelecidas estas premissas, cumpre evidenciar o reconhecimento do status de direitos fundamentais aos direitos dos trabalhadores. Tal constatação é pertinente na medida em que os mesmos, assim como os direitos da personalidade, também estão submetidos a exercícios de ponderação e relativização sempre que estiverem em colisão com outros direitos fundamentais, conforme já visto em item precedente. Contudo, não é apenas a condição de direito fundamental que tais matérias do Direito Privado compartilham; mais do que isso: ambos cumprem importante função social e, por isso mesmo, são fortemente protegidos contra atos de indisponibilidade
2. A globalização é um fenômeno complexo não podendo ser apresentada dentro do reducionismo econômico. 0 capital especulativo acaba ganhando do capital produtivo, fazendo com que, principalmente nos países periféricos, seja produzido o trabalho informal, em condições precárias, com consequências sociais e políticas destrutivas. Os novos procedimentos de proteção faz com que se perca a referência das garantias sociais, criando 0 individualismo extremado do trabalhador dentro dos processos produtivos. Lizst Vieira afirma que a globalização não é uma fatalidade histórica, tendo sido construida historicamente, de forma que devem sobrepor aos interesses econômicos questões que são mais importantes, como por exemplo, a defesa ambiental, os interesses locais e as necessidades e valorização das diversidades entre os povos (LIZST, Vieira. Cidadania e Globalização. Rio de Janeiro: Record, 1997). 
que lhe reduzam o conteúdo e aplicação. Neste contexto, como e em que bases se opera o exercício de ponderação entre os direitos fundamentais do trabalho e da personalidade quando, no caso concreto, do outro lado estiver o direito fundamental à autonomia privada, são perguntas que a seguir se buscará responder. (ANDRADE; GUDDE, 2013, p. 15)

O objetivo perseguido pelos autores acima é diferente do que ficou estabelecido para esse artigo. Porém, é importante aproveitar parte de seus estudos, no sentido de deixar balizado que as relações de trabalho são, em síntese, relações de direito privado, muito embora não exista por parte do trabalhador a vontade livre de se manifestar sobre querer ou não trabalhar e, muito menos, na maioria das vezes, sobre aquilo que quer fazer como trabalho e onde deseja realizar seu trabalho.

Portanto, a autonomia privada da vontade, que é o âmago da relação de direito privado e da própria realização do princípio da dignidade humana (liberdade de autodeterminação), na prática é quase inexistente quando se trata de o trabalhador decidir se irá ou não participar de uma relação de trabalho, considerando-se a necessidade de prestação de trabalho para a manutenção da sua vida e de sua família.

Da mesma forma, não existe autonomia de vontade do trabalhador, quando se refere a definir os procedimentos ou as técnicas que serão empregadas para a realização do trabalho.

Contudo, não é razoável, ainda que diante da desigualdade existente entre os sujeitos em uma relação de trabalho, que se subtraia do empregado qualquer possibilidade de manifestação de vontade, em defesa do princípio da irrenunciabilidade ou da condição absoluta dos direitos decorrentes das relações de trabalho serem classificados como Direitos Fundamentais. Principalmente quando a defesa da irrenunciabilidade absoluta se apresenta garantida pelo Estado nacional que de fato não tem mais o poder de oferecer qualquer garantia, seja no plano da prevenção ou da solução adequada dos conflitos de interesse laborais.

Ao se tentar comentar sobre um diferente prisma, e trazer um contraponto, dentro das linhas teóricas do neoliberalismo, percebe-se a construção da relativização daquilo que se chamou de direitos decorrentes da ordem pública, nota-se, assim, a necessidade de preservação da liberdade de vontade, o que deu asas aos processos de flexibilização e ou de regulamentação. 
Extrai-se desse breve comentário, embora a relativização dos direitos de ordem pública tenha contribuído para situações de flexibilização dos direitos originados das relações de trabalho, é certo também que a construção de dogmas no plano nacional, no sentido de inalterabilidade absoluta dos direitos laborais contribui negativamente para a criação de um pacto internacional para a proteção dos mesmos direitos.

Em outras palavras, o absolutismo no sentido de não possibilitar a manifestação de vontade dos trabalhadores pode contribuir para a estagnação do que se refere a construção de um sistema mais efetivo para a proteção dos direitos laborais, considerando que essa mesma proteção está presa ou somente poderá ser exercida diante da existência de um Estado nacional, que se apresente em condições de defender esses direitos. Sabe-se que isso não é mais possível, que significa que a linha da irrenunciabilidade dos direitos laborais ou o seu permanente engessamento por se tratar de direitos que compõe a ordem pública não está mais produzindo bons resultados.

Está sendo construído um cenário com vistas a "conviver" com as necessidades impostas pelo novo ambiente de trabalho, que está sendo edificado em um contexto muito diferente e distante daquele em que foram lapidados os princípios fundamentais do Direito do Trabalho (anteriormente relacionados), que traziam em si a condição de se tornarem estáticos, sob pena de, em assim não sendo, corromper-se a própria dignidade humana, realizáveis por meio de um Estado Nacional que detinha em parte o poder de aparente de torná-los realizáveis.

A questão aqui não é traçar um estudo para se identificar aquilo que pode ser ou não relativizado, em se tratando de direitos dos trabalhadores. A questão de início é ter claro que as relativizações estão ocorrendo em vários aspectos da prestação de trabalho, muito embora no plano pátrio ainda sejam compreendidas como direitos absolutos.

Um importante exemplo de relativização dos direitos provenientes do trabalho, no Brasil, são os resultados obtidos a partir das transações que se operam nas audiências na justiça do trabalho, nas quais o trabalhador acaba sendo coagido por vários motivos a aceitar propostas de acordos com valores ínfimos, em desacordo com aquilo que já se faz provado de forma líquida e certa nos autos a seu favor. A impressão que se tem, no caso da solução dos dissídios individuais do trabalho no Brasil, no foro judicial, é que o magistrado em vários momentos não exerce a tutela jurisdicional garantidora dos direitos indisponíveis. De acordo 
com o artigo $9^{\circ}$ da própria Consolidação das Leis do Trabalho, está o magistrado autorizado, diante da afronta a direitos indisponíveis, negarse a homologar o acordo que se pretende fazer perante aquele órgão. Porém, essa negativa é quase inexistente, ainda que diante de acordos trabalhistas que se aproximam de valores vis.

É importante transcrever relato feito por Ivan Alemão e José Luiz Soares (ALEMÃO; SOARES, 2009, p. 9) acerca dos processos de conciliação e os resultados produzidos:

Em 3 de dezembro de 2008, a companhia de energia elétrica da Paraíba, a Energisa, e os representantes do Sindicato dos Eletricitários da Paraíba (Sindeletric) homologaram acordo para o pagamento de uma dívida trabalhista de $\mathrm{R} \$ 37,4$ milhões, beneficiando cerca de 2000 trabalhadores, pondo fim a um processo que tramitava há mais de quinze anos e que representava a maior dívida trabalhista de uma empresa privada naquele estado. Essa conciliação foi comemorada como a maior já realizada pela Justiça Trabalhista paraibana - e uma das maiores em todo o país pelo seu elevado valor e importância histórica.

O contexto da conciliação decorreu de uma ação de cumprimento promovida pelo Sindeletric contra a Saelpa (atual Energisa) em razão da empresa não ter cumprido integralmente um dissídio coletivo de 1990 (processo 2092/87). Os primeiros cálculos do dissídio apontavam uma dívida de mais de $\mathrm{R} \$ 200$ milhões, que a Energisa conseguiu diminuir para $\mathrm{R} \$ 60$ milhões através de recurso julgado no TST que determinou o expurgo do Plano Collor dos cálculos. E foi esse valor - ainda não pago, mesmo após anos de processo transitado em julgado - que serviu de referência para a negociação nas audiências de conciliação. Num primeiro momento, a empresa ofereceu aos eletricitários apenas $29 \%$ do valor, o que foi considerado como insuficiente pelo sindicato. $\mathrm{O}$ acordo foi fechado com a Energisa oferecendo o pagamento de $51 \%$ do débito, assumindo ainda o custo dos honorários advocatícios, a contribuição para o sindicato Sindeletric e o FGTS. De acordo com notícias jornalísticas, a proposta foi amplamente discutida no sindicato e aprovada por quase unanimidade, em assembléia da qual participaram mais de 1300 reclamantes. O processo prosseguiu para onze dos 1960 reclamantes, os quais não aceitaram o acordo. Cerca de 160 trabalhadores já haviam morrido desde o início do processo e mais de 1000 não trabalhavam mais pela empresa. 
Conclui-se que, de um lado os direitos trabalhistas são irrenunciáveis e deve ser evitado outros processos de solução de conflitos de interesse. No entanto, de outro lado, no foro judicial, em processos de conciliação, independente da certeza ou liquidez dos direitos que estão sendo discutidos, aceita-se qualquer forma ou valores de conciliação, independentemente se os direitos postos para ser coercitivamente acordados tenham ou não se incorporado ao patrimônio dos trabalhadores. Sendo assim, qual conclusão deve ser tirada da condição de irrenunciabilidade ou daquilo que se extrai dos princípios de proteção ao trabalho humano?

Ao mesmo tempo, quando se pensa nos direitos provenientes das relações do trabalho como direitos fundamentais, sobrelevam as modificações que ocorrem nos procedimentos de produção, decorrentes em parte das novas tecnologias que, em várias situações, permitem que o trabalhador fique conectado constantemente a seu ambiente de trabalho ou leve consigo o próprio ambiente, ou mesmo que produza em várias regiões do planeta, muitas vezes sem a necessidade do deslocamento físico. Ou, ainda que compartilhe da mesma produção com outros trabalhadores, com diferentes condições de trabalho, de rentabilidade e por consequência, produzindo diferentes condições de vida.

Afirma-se que não obstante o avanço da tecnologia, em especial aquela que se volta para as comunicações, a cada dia está sendo produzido um mundo voltado para a individualidade em meio a uma competição predatória dos valores sociais, constituindo o chamado darwinismo social, que está associado diretamente aos novos procedimentos e formas de produção. ${ }^{3}$

E, por último, as formas arcaicas de solução dos conflitos provenientes do trabalho, que na maioria das vezes vêm a reboque no plano coletivo, decorrente de grave crise econômica ou no plano individual, com a intervenção do Estado Nacional, que não possui mais poder para regular, disciplinar as novas relações e formas de se produzir, mas que ainda mantém o monopólio para a solução jurídica das conflitos surgidos, ainda que na maioria das vezes de forma prejudicial para o trabalhador, considerando que mesmo em procedimentos de acordos judiciais, no plano individual, ainda mantêm-se os elementos individualidade e sobreposição do poder econômico.

A questão que se coloca é a seguinte: ainda que se defenda que a maior parte dos direitos provenientes das relações do trabalho sejam
3. Josecreto Costa de Almeida Pereira afirma: "É indiscutivel que no mundo globalizado a competitividade se exacerba, tendo como lema não a concorrência, mas a guerra. Essa guerra utiliza-se de todas as formas para dirimir os conflitos, frutos dessa lógica sem ética. A conseqüência mais visivel dessa realidade é o egocentrismo, ou seja, os individualismos na vida econômica, política e social, que terminam por transformar as pessoas em coisas (PEREIRA, Josecreto Costa de Almeida Pereira. Os paradigmas do mundo do trabalho na era da globalização. Sequência: estudos jurídicos e políti$\cos$ da Universidade Federal de Santa Catarina, vol. 24, no 46, Florianópolis, 2003, p. 55). 
absolutos, o referido entendimento não está sendo suficiente para impedir resultados danosos aos empregados, o que significa que se volta, mais uma vez, para a dura questão na qual a irrenunciabilidade se associa a um Estado nacional que não é mais garantidor dos mesmos direitos, como também preso ao tratamento individualizado, tanto em relação às pessoas, como em relação ao plano nacional, desconsiderando-se aquilo que ocorre internacionalmente.

Não obstante, nem por isso, ainda que diante de tantas transformações, pode se pensar nos direitos decorrentes das relações do trabalho como não fazendo parte dos direitos fundamentais, ou de concordar, de forma correta, no momento correto, com a limitação parcial da autonomia da vontade do trabalhador. E por conta dessa assertiva é que se torna necessário aperfeiçoar os métodos e as técnicas de prevenção e de modernização nas formas de proteção e solução dos conflitos do trabalho, porque o velho modelo baseado na irrenunciabilidade absoluta dos direitos trabalhistas protegidos por um Estado Nacional não está a tempo dando certo.

A questão mais importante para o momento não é adotar os princípios fundamentais do Direito do Trabalho, como supremos garantidores dos direitos surgidos a partir do trabalho, de forma que a sua realização impeça a adoção de novas práticas, dentro de nova dinâmica (transnacional), como, acontece com o supremo princípio da irrenunciabilidade.

Também, não é flexibilizar as normas de proteção do trabalho humano a ponto de desconstituí-las do valor de direitos fundamentais. A questão principal é propor o avanço da proteção, da prevenção dos conflitos e da solução de conflitos partindo-se da realidade posta, que compreende novos atores internacionais, um novo Estado Nacional, e novas formas de produzir, com o compartilhamento de várias empresas em um mesmo processo de produção, que não é mais localizado ou localizável, requerendo assim um novo comportamento por parte dos agentes envolvidos com a proteção dos Direitos Fundamentais, incluindo-se aqui a proteção do trabalho humano.

O novo contexto social internacional deve ser apreendido e, a partir dele, deve-se construir condições para a efetivação da proteção dos direitos decorrentes das relações do trabalho. 


\section{0 Estado Nacional nas relações de trabalho diante da possibilidade da criação de espaços públicos transnacionais.}

O impacto das novas tecnologias nas relações de trabalho é tema debatido em grande quantidade e profundamente, conforme se verifica na literatura jurídica, econômica, sociológica, e da administração principalmente. Para o mundo do trabalho, as novas tecnologias apontam para o aumento da produtividade, para a redução dos custos, com o objetivo único de alcançar maior competitividade, sem muita preocupação com as condições que estão sendo criadas para o trabalhador, ou seja, a precarização do trabalho humano.

E quando se fala em competitividade, considerando o mundo globalizado, fala-se em competitividade internacional. Ou seja, o mercado que vai ser disputado é o mundial, razão pela qual as grandes empresas, aqui chamadas de transnacionais, procuram regiões com baixo custo de produção, o que significa menores custos de transportes, menor proteção dos recursos ambientais e mão-de-obra com baixo valor, quase sem nenhum seguro social.

Segundo Bresser Pereira (1977, p. 239):

Agora as empresas multinacionais diversificam geograficamente sua atividade, em âmbito internacional, para maximizar usa taxa de expansão e sua taxa de lucro global. Instalam suas fábricas e escritórios de serviços onde o mercado seja mais favorável onde a mão-de-obra seja mais barata ou onde seja mais fácil obter pessoal técnico e administrativo, ou onde as matérias-primas sejam disponíveis, ou onde as facilidades de financiamento sejam mais favoráveis, e transferem os seus lucros através de diversos sistemas para onde os impostos sejam menores.

Considerando essas variáveis, coloca-se agora em estudo o papel do Estado Nacional, que também é algo evidente. Ou seja, o modelo de Estado Nacional procurado pelas transnacionais é aquele que intervém menos, em especial, na proteção dos chamados direitos sociais. O liberalismo pós-moderno pressupõe quase a inexistência dos Estados Nacionais ou o retorno para a sua situação primitiva de ser apenas um aparente garantidor dos direitos políticos.

É importante neste momento do estudo destacar as lições de João Bernardo (2000, p. 39): 
A globalização do capital alcançou um estágio superior e converteu-se em transnacionalização. Mais do que a junção de fronteiras, trata-se da passagem por cima das fronteiras. Por isso a terminologia de "companhias multinacionais", comumente usada deve ser substituída pela de "companhias transnacionais", que nos indica a especificidade deste tipo de empresas. Elas não juntam nações - passam por cima delas. Para compreendermos as principais implicações deste processo temos de proceder a uma mudança radical de perspectiva. Nós estamos habituados a considerar a economia mundial como um sistema de relações entre países, e é assim que a imprensa apresenta geralmente a questão. Todavia, se adotarmos o ponto de vista das sociedades transnacionais, verificamos que grande parte do comércio que as estatísticas oficiais contabilizam como externo é, na realidade, um comércio interno, constituído por transações entre matrizes e filiais. Esta alternação de perspectivas não ocorre apenas no plano econômico, mas no político também, porque as fronteiras entre países marcam a amplitude da esfera de ação de cada governo, e portanto a amplitude do Estado Restrito, enquanto a divisão entre as companhias transnacionais decorre diretamente do sistema de poder das empresas e, por isso, tem lugar no Estado amplo.

Observa-se a redução de importância do Estado Nacional, que passou a atuar em desigualdade de condições com as empresas chamadas de transnacionais, que acabam acumulando com seus tentáculos espalhados pelo mundo, um poder político maior que o próprio Estado. Também não pode ser perdido de vista os novos atores internacionais, que a cada momento estão surgindo, o que significa que maior número de entes participantes da vida internacional surgiu e está sendo construído a cada momento.

Dentro desse contexto, como trabalhar as formas de proteção e de solução de conflitos trabalhistas, considerando como paradigma o modelo reinante no direito pátrio, que é a solução dos conflitos de interesse por meio do Estado, também chamado de forma judicial de solução? Como manter as velhas técnicas diante de um ente que não é mais detentor de poder suficiente para regrar nem mesmo as suas relações internas de trabalho, considerando-se mais uma vez, no caso pátrio, o crescimento da informalidade e as demais formas de prestação de trabalho, que ainda não foram devidamente regulamentadas? Ou a queda das fronteiras, quando se trata de espaço para produzir? 
A primeira questão que se coloca é quanto à impossibilidade de ser debatida a proteção do trabalho humano separadamente das outras questões, que também guardam a mesma importância.

Segundo Jorge Mattoso (1995, p. 120):

Frente à crescente desestruturação sofrida pelo mundo do trabalho e aos problemas econômicos e sociais despertados pelo inicio da Terceira Revolução Industrial ainda realizada sob a modernização conservadora e cuja magnitude e desdobramento são ainda difíceis de discernir em sua totalidade, os trabalhadores e suas organizações sindicais e políticas se encontram na defensiva, sem oferecer alternativas capazes de articular as distintas forças que se opõem a este novo moinho satânico. A ofensiva do capital reestruturado que chama a si a tarefa de dirigir a sociedade capitalista sob as regras exclusivas da concorrência e do mercado auto-regulável em escala internacional, tem dificultado ainda mais a gestação de uma alternativa que aponte para uma nova sociedade capaz de gerar a emancipação crítica do trabalho social e uma nova hegemonia. Sem esta nova hegemonia, que extrapole os trabalhadores e seus tradicionais aliados, que incorpore novos agentes e novos temas sociais, e que contemple outras contradições que se apresentam crescentemente situadas além do local de trabalho e do processo de valorização, os trabalhadores dificilmente conseguirão protagonizar projetos nacionais e internacionais de transformação.

No entanto, essa mesma transnacionalidade do capital ou dos grandes conglomerados industriais acaba produzindo outra situação. Ou seja, crescentes alterações nos sistemas jurídicos nacionais, considerando o próprio reducionismo do Estado Nacional. Agora, como efetivar a proteção dos direitos laborais, considerando-se aquilo que já está acontecendo, no caso, um Estado Nacional que já se faz diminuto, com a desregulamentação crescente das relações de trabalho e o estímulo a processos reducionistas de atuação pública?

Alguns autores já tiveram a oportunidade de estudar esse tema, sendo importante aproveitar aqui algumas citações. Segundo Cruz e Bodnar (2011, p. 56): (...) o Estado e o Direito Transnacional poderiam ser propostos a partir de um ou mais espaços públicos transnacionais, ou seja, a criação de espaços públicos que possam perpassar estados nacionais. 
É importante deixar claro, examinando o artigo dos autores citados por último, que não se trata de criar um super Estado ou uma organização supraestatal. Seria por assim dizer o surgimento de novas instituições que transpusessem os espaços nacionais, tornando possível formar novos espaços que possibilitassem a discussão e o oferecimento de respostas satisfatórias aos problemas decorrentes de todas as modificações operadas nas relações de trabalho, a partir da nova configuração da produção.

Seria um espaço que adotaria práticas de cooperação e de solidariedade internacional, com destaque para temas sociais, em especial presos à construção da dignidade da pessoa humana, em que os Estados nacionais atuariam na condição de participantes, juntamente com outros entes internacionais, construindo uma regulamentação internacional de proteção, que envolvesse não somente a questão do trabalho, como já dito, mas também outras questões ligadas aos direitos fundamentais, que se ligam diretamente à proteção laboral, tornando-os de fato temas públicos da maior valia, de tal maneira que fosse intensificada uma política pública internacional, com ações estatais e de entes não estatais, por assim dizer privados, com poder de pressão internacional.

Dentro dessa visão de criação de espaços públicos com a atuação global, construiria uma força de proteção transnacional, que se sintetizaria em ações conjuntas, cooperadas e ordenadas, deixando de lado entes cuja formação e composição ultrapassada, como é o caso da ONU, deixaria a condição de ente centralizador, detentor do domínio das ações, assumindo o papel de participante, em meio a tantos outros entes.

É interessante, neste momento do estudo, demonstrar que a chamada matriz do Estado neoliberal se contrapõe à criação de espaços públicos transnacionais, voltados à discussão e à adoção de ações de integração. Isso se deve principalmente ao fato de que dentro do neoliberalismo o que impera é o individualismo exacerbado, que é a forma como as relações de trabalho estão se reorganizando, atualmente, considerando novos métodos e processos de trabalho.

O posicionamento adotado sobre a criação de espaços públicos de discussão vem no sentido contrário ao que hoje acontece. A adoção da existência de outros atores internacionais tem a possibilidade da construção de um coletivo internacional, que juntamente com o Estado Nacional, poderão ser capazes de construir , por assim dizer, um direito 
transnacional, sem o qual, no caso do tema apresentado, não será possível enfrentar questões como a crescente precarização do trabalho humano.

No plano nacional, não torna-se mais possível debater a precarização do trabalho humano, que dentro do prisma neoliberal, vê-se dominado pela ação da economia sob a matriz de liberdade de mercado, primando pela liberdade de vontade e de manifestação, que é um dos pontos de toque da própria democracia, que, nesse caso, apresenta-se apenas utilizando-se de uma roupagem democrática, mas cujos objetivos são muito diferentes.

Observe a contradição ou o erro existente do desenvolvimento do pensamento neoliberal, ainda que apoiado em elementos importantíssimos que fundamentam a democracia. No caso, a liberdade de vontade, enquanto expressão da própria cidadania, e enquanto formação de um mercado livre, sem qualquer interferência pública, que se apresenta como sendo capaz de produzir uma espécie de ordem natural social.

É importante destacar, ainda que de forma enfadonha, a matriz do chamado modelo neoliberal, para poder entender que ele não se coaduna com o mundo globalizado, por conta que dentro do individualismo nele imperante resume-se o desmantelamento do Estado Nacional. E quanto ao direito, preso ainda a velhos dogmas jurídicos, apresenta-o destacado de outros ramos do conhecimento, fazendo sobre ele sobrepor os interesses econômicos, desprovidos da necessidade dos resultados sociais.

Não se quer aqui afirmar que o modelo neoliberal não possua a representação do mundo globalizado. Tanto o representa, que as práticas neoliberais visam a reduzir custos nacionais, para o fim de criar condições de competitividade internacional, a partir do Estado Nacional modificado, ou seja, reduzido. Ocorre que a possibilidade da existência ou construção de espaços públicos transnacionais é inexistente dentro do modelo neoliberal. A transnacionalidade somente ocorre dentro do campo privado traduzido pela palavra competitividade internacional a partir da redução dos custos de produção, que foram conseguidos graças às práticas modernas de se produzir.

Talvez por conta da privatização da transnacionalidade é que se criou a expressão mercado mundial. Segundo Alexandre Moraes da Rosa (ROSA; AROSO, 2009), o conceito de mercado mundial originou-se na década de oitenta e início de noventa do século passado, levando-se em conta as seguintes características: criação de órgãos supranacionais, 
validade das normas internacionais sobre as nacionais, hegemonia do capital financeiro, que trouxeram como resultados, dentre vários, a flexibilização dos direitos trabalhistas e a precarização dos sistemas previdenciários.

O mais importante, segundo o autor, foi a criação de um sentido único de globalização, ou seja, como se fosse algo natural e uniforme para todas as regiões do planeta, produzindo efeitos homogêneos.

E esse é o ponto chave da discussão, uma vez que o modelo neoliberal verdadeiramente criou essa premissa. Ou seja, que a globalização, tratada sobre o prisma econômico apenas, é algo que ocorre da mesma forma em todo o planeta, apegando-se aos resultados por ela produzidos. Caso assim fosse, não haveria tanta desigualdade social e econômica no planeta. Não haveria o alargamento das diferenças entre os países chamados de centrais e de periféricos. Caso não fosse, já deveria estar ocorrendo a aproximação ou a redução das desigualdades econômico sociais no planeta. Porém, torna-se evidente que isso não está acontecendo.

Voltando à questão das relações de trabalho e aproximando-se um pouco mais do tema principal do presente artigo, como trabalhar a prevenção e a possível solução dos conflitos de interesse nessas relações, considerando a transnacionalidade que a cada dia mais se intensifica?

\section{A nova forma de produzir e a solução dos conflitos nas relações de trabalho transnacionalizada.}

Retomando alguns assuntos já tratados em páginas anteriores e aprofundando um pouco mais, a transnacionalização da economia e, por conseguinte, das empresas, seja na produção de bens, seja na prestação de serviços, verifica-se que está associada diretamente à adoção e ao aperfeiçoamento do modelo toyotista de organização do trabalho.

$\mathrm{Na}$ verdade, o aperfeiçoamento desse novo processo fez com que as empresas transnacionais localizassem, em vários países, estabelecimentos responsáveis etapa por etapa da produção, formando cadeia produtiva, seja para aquisição de bens materiais, matéria-prima, ou de bens de serviço, construindo, assim, uma cadeia logística de produção.

Também, fizeram subcontratações em cada país, de acordo com as vantagens obtidas, levando-se em conta os custos empresariais, em 
especial aqueles fatores já ditos anteriormente, como valor da mão-deobra, questões tributárias, proteção ambiental dentre outros. Em síntese, o critério utilizado é o da conveniência econômica para produzir.

As legislações nacionais ainda existentes de proteção ao trabalho humano não conseguem dar conta dessa nova realidade, a que se quer dar o nome de globalização, considerando não somente a nova logística da produção, como também a sazonalidade na produção e a movimentação de trabalhadores de uma região para outra, em busca do emprego ou de melhores condições de trabalho.

Segundo Stelzer (2011, pp. 18-19):

A globalização (ou mundialização) é um processo paradigmático, multidimensional, de natureza eminentemente econômicocomercial, que se caracteriza pelo enfraquecimento da soberania dos Estados-nacionais e pela emergência dos novos focos de poder transnacional à luz da intensificação dos movimentos de comércio e da economia, fortemente apoiado no desenvolvimento tecnológico e no barateamento das comunicações e dos meios de transportes, multiplicando-se em rede, de matriz, essencialmente heurística.

No plano comercial, levando em conta o perfil dessa nova realidade, desenvolvendo-se a largos passos aquilo que se intitulou chamar de arbitragem internacional, considerando a necessidade surgida de um meio de solução de litígio comercial que seja rápido, tendo como objeto o direito material disponível, de caráter patrimonial, o que excluiria direitos de estado, questões tributárias, de família, ligados aos direitos da personalidade, dentre outros. Questões como, direitos provenientes da relação de trabalho, da forma como hoje são apresentadas no direito pátrio, considerando a sua característica de indisponibilidade, também não seriam tratadas pela arbitragem internacional, ressalvando-se o caso de direitos coletivos do trabalho, por força do artigo 114, parágrafo $1^{\circ}$, da Constituição Federal.

A Organização Internacional do Trabalho, em um contexto de mobilização pela proteção dos Direitos Humanos, em nível internacional, tem construído uma linha orientadora para a solução dos conflitos de interesse laborais no plano internacional, fundada nos seguintes elementos: a) promoção do diálogo social; b) autocomposição; c) incremento das formas alternativas de solução dos conflitos (que não 
através do Estado), e d) desenvolvimento de mecanismos de prevenção dos conflitos.

De imediato já é possível detectar, comparando a linha orientadora da OIT com a construção feita no direito pátrio, que existe um forte incentivo a formas alternativas de solução dos conflitos do trabalho, estando assim em desacordo com o que vem ocorrendo no Brasil. Conclui-se que, no Brasil, a visão egocêntrica do Estado Nacional tornase perceptível, contribuindo para o afunilamento em torno da forma judicial à solução dos conflitos laborais. Observa-se que o paradigma Estado provedor, regulador e solucionador das controvérsias mantém-se intacto no Brasil, valendo-se do paradigma irrenunciabilidade absoluta dos direitos laborais.

Considerando as dificuldades enfrentadas pelos Estados Nacionais diante da transnacionalidade, por várias vezes debatidas, neste artigo, conclui-se que de forma circular, retoma-se ao mesmo problema. Ou seja, a nova logística de produção faz com que as formas locais não deem mais resposta satisfatória aos conflitos laborais, surgidos dessa realidade globalizada, em especial a forma judicial. E a questão que se coloca é que o desenvolvimento dessas formas de solução da conflitualidade no plano internacional funciona sob o caráter da complementaridade, levando-se em conta que as soluções oferecidas pelo Estado nacional apresentam-se em um primeiro plano, e a forma internacional em um segundo, muitas vezes como se fossem instâncias de solução.

Parece que fica difícil dividir a solução dos conflitos entre instância nacional e global, considerando a metamorfose ocorrida no mundo do trabalho, como se fossem sistemas autônomos de poder. Isso porque a lógica da produção não é mais local, ainda que, diante de situações em que, de forma material, a empresa onde o trabalhador esteja vinculado por meio de uma relação de emprego não detenha filial em outros países ou não participe explicitamente de rede internacional de produção.

Mesmo a empresa que se apresenta genuinamente nacional, estará interagindo com o mercado internacional ou sofrendo diretamente sua interferência, o que significa que no plano nacional e internacional, ela se relaciona com vários ambientes, o que a torna também internacional em virtude das suas ações.

A questão aqui não é negar ou desvalorizar os sistemas nacionais de proteção e de solução dos conflitos originados nas relações de trabalho. Trata-se de demonstrar que a manutenção ou não dos direitos 
laborais e, por conta disso, também a solução dos conflitos do trabalho estão diretamente vinculados à efetividade da proteção dos direitos decorrentes das relações do trabalho no plano global. Não se trata de discutir a existência de autonomia ou não da vontade do trabalhador, considerando o princípio da irrenunciabilidade dos direitos trabalhistas e sim, a construção de um espaço no qual o tema proteção do trabalho humano, juntamente com outros temas, apresentem-se no plano internacional, com liberdade para serem debatidos, e construído um sistema de proteção internacional.

E para que essa efetividade ocorra, os direitos laborais locais ou nacionais estão vinculados ou à dependência do envolvimento de atores internacionais, incluindo aqui o Estado Nacional na condição de ator internacional e não como detentor único, como é o caso brasileiro, de intervir nas relações de trabalho, mesmo não mais possuindo o poder de intervenção. Volta-se à questão da construção de espaços públicos transnacionais, com a participação de vários entes internacionais não estatais, capazes de produzir a efetividade, como também os procedimentos para a solução dos conflitos transnacionais e locais do trabalho.

Segundo Trubeck (2000, pp. 1.187-1.209), os sistemas internacionais podem, ao mesmo tempo, assumir caráter complementar e reforçar os sistemas nacionais, considerando o processo de interação, como se fosse a retro alimentação, considerando a ligação direta entre os sistemas, consistindo num conjunto de estruturas e variadas normas que sustentam práticas nacionais, podendo inclusive substituí-las. Voltase a afirmar que os objetivos e a estrutura aqui apresentados somente se desenvolvem na medida em que vários atores internacionais possam participar de sua construção.

Continuando o estudo, segundo Maria Pessoa Henrique (2007, p. 47), existe importância crucial das empresas transnacionais para a adoção de novas práticas, criticando ao final a baixa eficácia das práticas internacionais por conta da falta do engajamento de outros atores sociais internacionais:

Ainda relativamente à emergência de um espaço mundial nos sistemas de resolução dos conflitos laborais, deve referir-se a crescente importância das empresas transnacionais, cuja influência sobre a conflitualidade laboral se reconhece em mecanismos e 
instrumentos como a criação de zonas francas, códigos de conduta das multinacionais, políticas de recursos humanos, arbitragem transnacional, subcontratação, deslocalização e criação de regimes internos de boas práticas das multinacionais, indutores de uma competitividade entre as suas várias sucursais. Com elevado potencial emancipatório, mas com reduzida eficácia prática, deve mencionar-se o espaço da comunidade transnacionalizado, o qual através das ONG e do sindicalismo internacional se constitui em mais um elemento associado à dimensão transnacional da resolução dos conflitos laborais.

A proteção aos direitos laborais ainda se apresentam compreendidos no plano nacional, restrito à função do Estado Nacional, o que é grande erro. E as práticas, no caso do Brasil, para a solução dos conflitos do trabalho, são de natureza individual, por meio da solução judicial, quase sempre restrita à aplicação da norma nacional.

Na verdade, esse panorama é quase um padrão, a partir do momento em que o direito laboral é violado ou quando um preceito legal interno é descumprido, o mesmo ocorrendo com os demais, guardando referência nacional, presos ao Estado nacional, por conta que o próprio conceito de cidadania está preso à cidadania local, nacional e não internacional. E a sua solução situa-se majoritariamente no plano nacional e individual.

E são justamente essas mudanças que precisam ser operadas, deixando o plano local, com o corte em cidadania nacional, passando para o conceito de cidadania internacional ou transnacional, deslocando a centralidade do Estado para o plano coletivo internacional. Isso significa adotar para a proteção dos direitos sociais a mesma evolução já adotada pelo capital, conforme instigado na primeira parte do desenvolvimento desse artigo.

Segundo Maria Pessoa Henriques (2007, pp. 48 e 49):

Fenômenos, como: o desemprego, o trabalho precário, o trabalho infantil, a falta de condições de trabalho, a discriminação étnica e sexual, etc.; resultam de uma matriz de combinações entre, por exemplo, o espaço local/nacional e o espaço global, entre os processos de transnacionalização do capital e os sistemas de Direito do Trabalho nacionais, entre as dinâmicas das empresas multinacionais e o desempenho dos Estados nacionais. Daí que 
redescobrir o trabalho, quer como categoria analítica, quer como problema social, é fundamental para a efectividade dos direitos humanos do trabalho.

É prudente afirmar que o crescimento da legitimidade da OIT, frente aos Estados a ela vinculados, pode ser um dos elementos mais importante para a criação dos chamados espaços públicos internacionais de discussão sobre a proteção do trabalho humano. Atualmente, muito embora os países pactuantes da OIT não sejam obrigados a ratificarem suas Convenções Internacionais, ainda assim, elas servem como parâmetros, princípios lógicos para o início da construção de um sistema integrado de proteção internacional dos direitos fundamentais do trabalho, principalmente levando-se em conta um dos principais objetivos do neoliberalismo, que é a desregulamentação das relações de trabalho no plano nacional.

Acontece que a OIT não é suficiente para implementar sozinha esse grande objetivo. No plano das Convenções Internacionais do Trabalho, concebidas em um primeiro momento sob o aspecto mais educativo, desprovidas de papel sancionatório, deve-se aliar outras questões que se ligam umbilicalmente, como, a não discriminação étnica e ou religiosa, a construção de fontes alternativas de energia, a proteção ambiental, a mudança dos paradigmas de consumo, a produção de empregos verdes, dentre outros temas.

E, para que se alcance a efetiva proteção, deve-se construir uma rede internacional de proteção, integrada com ações conjuntas, conforme será estudado no próximo item.

\section{Da necessidade da construção de um padrão internacional de proteção ao trabalho humano}

Retomando alguns pontos importantes deste estudo, tem-se o reducionismo do Estado Nacional e a necessidade da adoção de leitura global para que se alcance a efetividade da proteção do trabalho humano, incluindo-se aqui também a forma de solução de conflitos do trabalho, enquanto fazendo parte dessa mesma proteção.

O ideal a ser alcançado, quando se fala em proteção do trabalho humano, é construir um sistema internacional de garantias mínimas que 
passa ser aplicado de forma global. Ou seja, a construção e efetivação de direitos fundamentais do trabalho, que possam ser aplicados a todos os trabalhadores do mundo. Esse objetivo foi, em síntese, o que levou à própria criação da OIT (Organização Internacional do Trabalho) em 1919.

Para a época de sua criação, não havia mecanismos, nem tecnologia e práticas empresariais que viabilizassem a construção de um sistema internacional de garantias, salvo talvez naquilo que era conhecido como mundo ocidental. Observa-se que a globalização não pode ser vista somente enquanto algo destrutivo das condições de trabalho (inclusive essa é a visão que proliferou), considerando que a evolução tecnológica que a promoveu, dentro de um processo de integrações regionais, foi também o que possibilitou retomar o estudo sobre a necessidade e a possibilidade da construção de padrões de proteção internacionais para o trabalho.

No caso do Brasil, é inconteste que as Convenções Internacionais do Trabalho promoveram a inclusão do ordenamento jurídico interno, por meio dos processos de ratificação, de vários princípios protetivos do trabalho humano. Mesmo o Brasil não tendo ratificado todas as Convenções, aquelas que ainda não foram recepcionadas não deixam de valer como marcos teóricos para a construção legislativa nacional.

Também vale citar, como exemplo, as chamadas "queixas" (denúncias) feitas à OIT contra o Estado Brasileiro, em especial sobre temas como proibição do trabalho infantil, uso desordenado do interdito proibitório (afronta ao princípio da liberdade sindical), contra o trabalho escravo (violação ao princípio da liberdade e da dignidade), que contribuíram para a adoção de práticas especiais internas representativas, no sentido de corrigir a afronta desses direitos fundamentais.

No entanto, no que se refere ao desenvolvimento de outros procedimentos para a solução dos conflitos decorrentes do trabalho, no caso do Brasil, não houve internalização de novos procedimentos, considerando a rejeição doméstica pelo uso da arbitragem no caso dos conflitos individuais do trabalho e a própria inexistência da utilização do mesmo procedimento para os conflitos coletivos do trabalho, muito embora, no caso dos conflitos coletivos, exista até determinação constitucional para que se aplique a arbitragem (artigo 114, parágrafo $1^{\circ}$, da Constituição Federal).

É importante demonstrar, seguindo o desenvolvimento do presente estudo, que para a construção de parâmetros internacionais, 
incluindo aqui o desenvolvimento de novas formas de solução de conflitos do trabalho, pressupõe não somente a construção de Convenções Internacionais do Trabalho,como por exemplo, Convenções Internacionais do Trabalho $\mathrm{n}^{\circ} 98$ e 154 da OIT, que, no caso específico da solução de conflitos, recomendam o emprego da negociação coletiva como forma de solução, mas também a inclusão do próprio Estado, no caso o brasileiro, em espaços públicos, que juntamente com outras questões ligadas aos direitos fundamentais, construa internamente a base jurídica e política para o desenvolvimento de novos procedimentos para a solução de conflitos laborais, como também a prevenção com vista à efetividade dos direitos fundamentais do trabalho.

Essa mesma afirmativa se aplica, levando-se em conta as variáveis existentes e os temas estudados, a outros Estados Nacionais. Uma crescente produção internacional num primeiro momento, fomentada por entes públicos e privados, vinculada a outras questões fundamentais que não somente e diretamente à proteção do trabalho humano, podem formar parâmetros normativos e políticos globais.

Não se trata da relativização dos princípios do Direito do Trabalho, e sim, da tomada de posição frente aos mesmos princípios, levando-se em conta o contexto global e a multidisciplinaridade temática, evoluindo para a construção de uma proteção unificada em favor dos direitos fundamentais. Em outras palavras, somente por meio de uma proteção unificada é que se poderá proteger o trabalho humano.

É sabido que o Conselho de Direitos Humanos (iniciou os trabalhos em 2006), órgão subsidiário da Assembleia Geral da ONU, equiparado ao Conselho de Segurança e ao Conselho Econômico e Social, seria talvez o foro mais indicado para a discussão e a elaboração de propostas, para a efetivação da proteção dos direitos fundamentais do trabalho.

Não se quer aqui desqualificar o citado Conselho. Acontece que não se pode resumir a criação de espaços públicos, revisitando órgãos institucionalizados formalmente ao longo do tempo, a ponto de atribuir a eles a exclusividade para a realização desses valores.

O que se defende neste estudo é o aproveitamento dos espaços existentes e a criação de outros, até porque a ONU, como já se afirmou, não pode continuar a manter o monopólio do processo de realização dos direitos humanos. Inclusive, essa é uma das críticas aqui lançada. 
Atualmente, é possível citar como exemplo de espaço público multidisciplinar o Fórum Econômico Mundial, que, entre assuntos como terrorismo, conflitos militares, política nuclear, mercado financeiro, política fiscal, também trata de investimentos privados em países que apresentam grande índice de pobreza, por ser esse um grande entrave para investimentos estrangeiros (no caso do Brasil) e para reforma social. Uma das alternativas para a solução da guerra civil que se instalou na Síria foi tratada como a necessidade da melhoria das condições de vida dos seus cidadãos, passando pela necessidade da geração de empregos ${ }^{4}$.

Uma questão que se desponta, ainda tratando das ações da OIT, que está de acordo com a proposta de unificação da defesa dos direitos fundamentais, ocorreu principalmente a partir de 1990, com a construção do conceito de trabalho digno.

$\mathrm{Na}$ conceituação de trabalho digno, concentrou-se a necessidade da efetivação dos direitos fundamentais, na qual por meio do trabalho ficaram fixados os objetivos a serem alcançados, valendo citar: a realização de um trabalho que possa produzir a autoestima de quem trabalha, com remuneração que permita a proteção social da família, que propicie ao trabalhador a oportunidade de participar de decisões que afetem sua vida e da coletividade, nas quais estão inseridas, igualdade de tratamento sem diferenciação de sexo, etnia, linha religiosa ou nacionalidade.

Portanto, comprova-se que o trabalho digno promove a realização dos direitos fundamentais, compreendendo-o no plano globalizado ou transnacional e, por consequência, no plano nacional.

Para Gosdal (2006, p. 38), tratando sobre o conceito de dignidade:

4. Os conflitos internos em vários paises possuem como principal causa a miséria que se instaura para a população, como altas taxas inflacionárias, juros altos, falta de alimentos, falta de empregos e não questões éticas ou religiosas, não querendo é claro desconsiderar ou reduzir os últimos dois fatores. Davos reforça o abismo entre Irã e Israel. Disponível em: http://www.dw.de/davos-refor\%C3\%A7a-abismo-entre-ir\%C3\%A3-e-israel/a-17383770. Acesso em: 24 jan. 2014.
Pela utilização que tem sido feita da dignidade e, ao mesmo tempo, pela necessidade de que seja observada nas relações entre os indivíduos, é preciso analisar se é norma, princípio, ou apenas valor fundante dos direitos fundamentais. $\mathrm{O}$ esclarecimento acerca da inserção da dignidade como direito fundamental, sem retirá-la do contexto dos direitos humanos, estando vinculada tanto aos tratados e convenções de direito internacional, como ao ordenamento jurídico interno, permite que se passe à consideração da dignidade não apenas como um princípio, de aplicabilidade duvidosa, mas também e, de maneira não excludente, como direito e necessidade. 
Tem-se a construção, a partir do trabalho digno, de subsistemas para cada um dos objetivos citados, os quais se apresentam integrados, nos quais um alimenta o outro dentro do plano internacional, irradiandose para o plano nacional, sem a existência da sobreposição de sistemas. De forma diferente, compondo um conjunto de direitos e de ações para a efetivação desses direitos, deixando de existir espaços geográficos sem proteção e ao mesmo tempo criando matrizes internacionais de proteção ao trabalho humano levando-se em conta o conjunto dos Direitos Fundamentais.

Para Kátia Arruda (1998, p. 44):

Uma importante forma de caracterizar um direito como fundamental prende-se a sua contribuição para a dignificação do homem, que se projeta na liberdade individual, no convívio social e em todas as esferas possíveis de alcançar a plenitude do desenvolvimento humano, daí porque os direitos sociais são fundamentais, atingindo também as pessoas na produção e potencialização de sua personalidade.

A partir da construção do trabalho digno, tem-se também a construção de um meio ambiente do trabalho e de um meio ambiente externo ao trabalho sustentável, ou seja, com promoção ambiental (Direitos Fundamentais de terceira geração), incluindo aqui a redução ou a eliminação dos riscos do trabalho e a promoção e construção de uma consciência coletiva de proteção.

No que diz respeito à atividade empresarial, associa-se à produção econômica, necessariamente, a promoção conjunta do desenvolvimento social sustentável. A empresa comporá, juntamente com outros agentes de promoção social, ações sociais internacionalizadas, criando um padrão globalizado de atuação empresarial.

Significa que, não importa o local onde a empresa vai produzir, ela deverá estar focada no cumprimento dos padrões internacionais de produção, não permitindo assim a criação de "ilhas" geográficas, onde os direitos laborais não estejam protegidos, independentemente da postura do Estado Nacional, por conta que as suas ações são internacionalizadas e não estará sendo tratado apenas o trabalho humano e sim o conjunto dos Direitos Fundamentais, por meio da ação de vários atores internacionais que não apenas os entes atualmente constituídos. 
Em outras palavras, trata-se da visão holística, que pressupõe a interdependência e a indivisibilidade dos direitos humanos. Sendo indivisíveis, seu tratamento também precisa ser indivisível, formando uma estrutura, na qual o valor de cada direito somente existirá se reforçado pelo valor de outro direito. Isso quer dizer que o trabalho digno somente poderá ser defendido mediante a adoção de um modelo internacional (global) de defesa desses mesmos direitos humanos, com a participação da diversidade de atores internacionais.

Portanto, questões como a flexibilidade ou não flexibilidade, intervenção ou não do Estado nas relações de trabalho, irrenunciabilidade no plano individual, sem retirar sua importância, acabam se tornando questões secundárias frente à nova forma e aos procedimentos que devem ser adotados para a efetiva proteção dos direitos laborais.

Em outras palavras, a construção de um trabalho digno prende-se à necessidade das seguintes mudanças: a)proteção no plano internacional e nacional, formando um todo e não instâncias de proteção; b) tratamento coletivo e ou difuso no plano internacional; c) construção de mecanismos variados de proteção; c) construção de novos espaços públicos internacionais; d) legitimação de múltiplos agentes de participação; e) retirada do Estado Nacional, enquanto centralizador das decisões, e; e) integração da proteção laboral com a proteção de outros Direitos Fundamentais, enquanto compondo um todo único e indivisível, por meio das mesmas ações, chamadas aqui de integrativas.

\section{Conclusão}

O presente artigo partiu do contexto global de produção, considerando as estratégias e ou as redefinições da empresa, nominada aqui como empresa transnacional, que levou à geração de um novo procedimento ou estrutura de produção de bens e de prestação de serviços.

Ocorre que a proteção ao trabalho humano, partindo do modelo criado pelo Estado brasileiro baseia-se ainda na intervenção direta ou indireta do próprio Estado, nas relações de trabalho, partindo-se do princípio de que o Estado nacional é ainda o maior garantidor desses direitos, sempre se referindo ao plano nacional, muito embora não seja mais possível pensar a proteção dos direitos provenientes das relações 
laborais no plano local ou nacional apenas, principalmente por conta das mudanças no modo de produzir imprimido no contexto internacional a contar da segunda metade do século XX.

Diante dessas constatações e considerando a inoperância constante e crescente do Estado, acumulado com o emprego das novas tecnologias para se produzir, lançou-se a seguinte proposição: construir um sistema internacional de proteção dos Direitos Fundamentais, nele incluídos os direitos de origem laboral, com a criação de novos espaços públicos internacionais e a participação do maior número possível de atores internacionais, de forma a trabalhar a proteção do trabalho humano dentro do contexto dos outros valores que constituem os Direitos Fundamentais.

Nesse procedimento, compreenderam-se tanto as formas de prevenção, como de solução dos conflitos provenientes das relações do trabalho, tomando-as como se fossem todas as formas possíveis de prestação do trabalho humano. Para tanto, foi apresentada a necessidade de serem revistos alguns dos chamados princípios universais de proteção do trabalho, sem, contudo, apoiar o relativismo dos mesmos princípios, mas tecendo críticas no sentido que eles precisam ser interpretados de forma atualizada. Acontece que muito deles já foram desfigurados pela própria prática, como acontece com os acordos ou transações que estão se operando, perante o órgão jurisdicional do trabalho no Brasil.

Em muitas situações, a forma absoluta de tratamento dos princípios protetores, como acontece, por exemplo, no Brasil, como é o caso da irrenunciabilidade dos direitos trabalhistas no plano negocial extrajudicial ou a não adoção de outras formas de solução dos conflitos do trabalho, acabam se somando de maneira negativa à tentativa de alterar o centro das discussões.

O Estado Nacional não pode mais deter o monopólio da proteção dos direitos laborais. Foi proposta a criação de novos espaços públicos que propiciem os debates e proposições, incluindo-se a proteção do trabalho humano enquanto um valor pertencente a um conjunto de outros valores denominados Direitos Fundamentais, revestindo-os de um tratamento sistêmico, com a participação de número maior de atores internacionais, incluindo entes de direito público e privado, com ações coordenadas de proteção a todos esses valores. 
A lógica do capital propôs a construção de um mundo sem fronteiras, com múltiplas modulações, quando se pensa em formas de produzir; assim sendo, proteção do trabalho humano, percebe-se que ela somente será efetivada quando ganhar também os elementos da transnacionalidade, de forma atemporal, com a interdependência e indivisibilidade do tratamento dos Direitos Fundamentais, criando-se, a partir desses marcos, mecanismos efetivos de proteção.

O desenvolvimento econômico com desenvolvimento social não se circunscreve mais a ações locais ou nacionais de proteção ou intervenção do Estado. Também outros atores precisam participar deste processo de redefinição dos métodos e das práticas de efetivação dos direitos laborais.

Em síntese, o que precisa é transformar, dar o aspecto dinâmico de criação e de desenvolvimento de institutos, que, de forma efetiva, possam apreender a realidade hoje existente para, partindo dessa apreensão, promover novas formas ou métodos ou procedimentos, interagindo de forma dinâmica com vários espaços públicos e privados, constituindo assim uma rede articulada, com mecanismos que atuem de forma constante na proteção do conjunto dos valores que constituem os Direitos Fundamentais, incluindo-se a defesa do trabalho digno. 


\section{REFERÊNCIAS}

ALEMÃO, Ivan; SOARES, José Luiz. Pressão por conciliação dificulta acesso à justiça. Conjur - Consultor Jurídico, 25 de novembro de 2009. Disponível em: http://www.conjur.com.br/2009nov-25/pressao-conciliacao-revela-chicane-acesso-justicatrabalho?imprimir=1. Acesso em: 10 jan. 2014.

ANDRADE, Fábio Siebeneichler de; GUDDE, Andressa da Cunha. O desenvolvimento dos direitos da personalidade, sua aplicação às relações de trabalho e o exercício da autonomia privada. Cadernos de Pós Graduação em Direito/UFRGS, volume VIII, número 02, ano 2013.

ARRUDA, Kátia Magalhães. Direito constitucional do trabalho: sua eficácia e o impacto do modelo neoliberal. São Paulo: LTr, 1998.

BERNARDO, João. Transnacionalização do Capital e Fragmentação dos trabalhadores. Aindahá lugar para os sindicatos? São Paulo: Boitempo, 2000.

CATTANI, Antonio David. Trabalho e autonomia. Petrópolis, RJ: Vozes, 1996.

CRUZ. Paulo Márcio; BODNAR. Zenildo. A transnacionalidade e a emergência do estado e do direito transnacionais. In:Direito

e Transnacionalidade. Paulo Márcio Cruz, Joana Stelzer (orgs). 2009, Curitiba: Juruá, 2011.

DELGADO, Maurício Godinho. Curso de Direito do Trabalho. 12 ed. São Paulo: LTr, 2013.

GOSDAL, T. C. Dignidade do trabalhador: um conceito construído sob o paradigma do trabalho decente e da honra. 2006. 195f. Tese (Doutorado em Direito) - Programa de Pós-Graduação em Direito, Universidade Federal do Paraná. Curitiba, 2006. Disponível em: http://dspace.c3sl.ufpr.br/dspace/bitstream/ handle/1884/4675/THEREZA\%20CRISTINA20GOSDAL. PDF;jsessionid=F7574BEF17D81611DD6688EE7671C2AC?sequence $=$, página 38. Acesso em: 21 mar. 2012.

HENRIQUE, Maria Pessoa. Desafio à Regulamentação Internacional das Relações Laborais: A OIT e o caso português (dissertação de mestrado). Universidade de Coimbra. Coimbra: 2009.

IANNI, Octávio. A era do globalismo. Rio de Janeiro: Civilização Brasileira, 1997.

LIZST, Vieira. Cidadania e Globalização. Rio de Janeiro: Record, 1997. 
MACHADO, João Bosco M. Integração Produtiva: referencial analítico, experiência e lições para o Mercosul, p. 03 e 04, Disponível em: http://www.eclac.cl/brasil/noticias/ noticias/5/35375/Integra\%C3\%A7\%C3\%A3oProdutivaJoao_ Bosco.pdf. Acesso em: 13 jan. 2014.

MATTOSO, Jorge. A desordem do trabalho. São Paulo: Scritta, 1995.

ROSA, Alexandre Morais da; AROSO LINHARES, José Manuel. Diálogos com a Law \&Economics. Rio de Janeiro: Lúmen Júris, 2009.

PEREIRA, Luiz Carlos Bresser. Estado e subdesenvolvimento industrializado. São Paulo: Editora Brasiliense, 1977.

PEREIRA, Josecreto Costa de Almeida Pereira. Os paradigmas do mundo do trabalho na era da globalização. Sequência: estudos jurídicos e políticos da Universidade Federal de Santa Catarina, vol. 24, no 46, Florianópolis, 2003. Disponível em: https:/ / periodicos. ufsc.br/index.php/sequencia/article/view/15291/13894. Acesso em: 05 jan. 2014.

RODRIGUES, Américo Plá. Princípios do Direito do Trabalho. São Paulo: LTr, 1978.

STELZER, J.O fenômeno da transnacionalização da dimensão jurídica. In: CRUZ, P. M.; STELZER, J. (Org.). Direito e transnacionalidade. Curitiba: Juruá, 2011.

TRUBEK, David M. Transnationalism in the Regulation of Labour Relations: International Regimes and Transnational Advocacy Networks. Law and Social Inquiry, Vol. 25, $\mathrm{n}^{\circ} 4$. University of Chicago, 2000.

Lourival José de Oliveira

Doutor em Direito das Relações Sociais (PUC-SP)

Docente do Programa de Mestrado da Universidade de Marília; docente do Curso de Graduação da Universidade Estadual de Londrina; docente e coordenador de Curso da Faculdade Paranaense; Consultor de várias revistas; advogado em Londrina e-mail: Lourival.oliveira40@hotmail.com Currículo lattes: http://lattes.cnpq.br/0909877454780329 